\title{
Numerical Study Effect of Secondary Air Mass Flow to Characteristics of Circulating Fluidized Bed Boiler
}

Ahmad Tarmizi $^{1}$, Giri Nugroho ${ }^{1}$, Achmad Syaifudin ${ }^{1}$, Bambang Sudarmanta ${ }^{1}$ pyrolisis, gasification, or combustion.[4].

\section{LITERATURE REVIEW}

is the main factor needed during the combustion process. The amount of air entering the combustion chamber will determine the Air Fuel Ratio (AFR). Air Fuel Ratio (AFR) is what will determine whether the process takes place

In 2010, Nan Zhang conduct a study entitled "3D CFD Simulation of Hydrodynamics of 150 MWe Circulating Fluidized Bed Boilers". [5] In this study, a simulation using the energy minimization multi-scale model (EMMS) was performed. The study was modelled as a three dimensional (3D), full-loop, time-dependent simulation of hydrodynamic at 150 MWe power, circulating fluidized bed (CFB) boiler. The result of this research is pressure distribution at circulation area, volume fraction profile, solid vertical velocity, and non-uniform distribution in 2 parallel cyclones.

Mass Flow, Fluidization, Multiphase.

\section{INTRODUCTION}

Electricity consumption in Indonesia continues to increase along with the increasement of national economy.[1] With this increaseament, it is also necessary to improve the efficiency and reliability of power plant, so the operation of power plant can fulfil energy necessary. One important component affecting the performance of a plant is the boiler. At Bangka Steam Power Plant (PLTU Bangka), the type of boiler that operate is Circulating Fluidized Bed Boiler (CFBB). With the floating characteristics of CFB boilers, this type of boiler makes it possible to carry out combustion processes with low rank coal.[2] In addition, with the presence of hot particles that continue to circulate, making the process of heat transfer in the boiler will be more efficient. In CFB boilers, the amount of secondary air entering the boiler affects the characteristics of the flow inside the boiler.[3] Changes in the amount of secondary air can affect the fluid flow characteristics in the boiler and the combustion process. These characteristics can be analyzed with the distribution of pressure and velocity profile in the boiler. In addition, air

\footnotetext{
${ }^{1}$ Ahmad Tarmizi, Giri Nugroho, Achmad Syaifudin, Bambang Sudarmanta are with Department of Mechanical Engineering, Faculty of Industrial Engineering, Institut Teknologi Sepuluh Nopember (ITS), Kampus ITS Sukolilo, Surabaya 60111, Indonesia. E-mail: tarmizi.plg@gmail.com; giri@me.its.ac.id; saifudin@me.its.ac.id;
} sudarmanta@me.its.ac.id.

\section{METHOD}

The object of this research is Steam Power Plant (PLTU) Bangka at operating condition 22,5 MW in 75\% MCR (maximum continuous rating). The type of boiler in PLTU Bangka is Circulating Fluidized Bed (CFB) Boiler. [6] Inside the boiler, there are 3 types of working phases: coal, air, and sand that serves as a medium of heat and fluidized bed. If there is no sand in the CFB type boiler then the combustion will not occur perfectly and the combustion will not occur uniformly. It is this sand that distinguishes CFB type boilers from other types of boilers.

\section{A. Geometri and Mesh}

The modeling domains used are boundary condition type of mass flow inlet for primary air amounted to 2 pieces, secondary air amounted to 16 pieces, and coal inlet amounted to 3 pieces. For flue gas outlet using boundary condition type pressure outlet. 

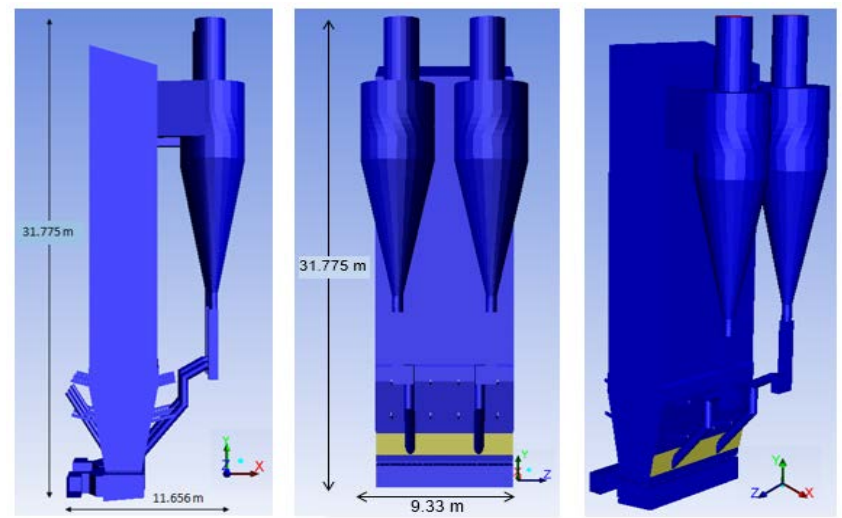

Figure 1. Geometri of CFB boiler PLTU Bangka
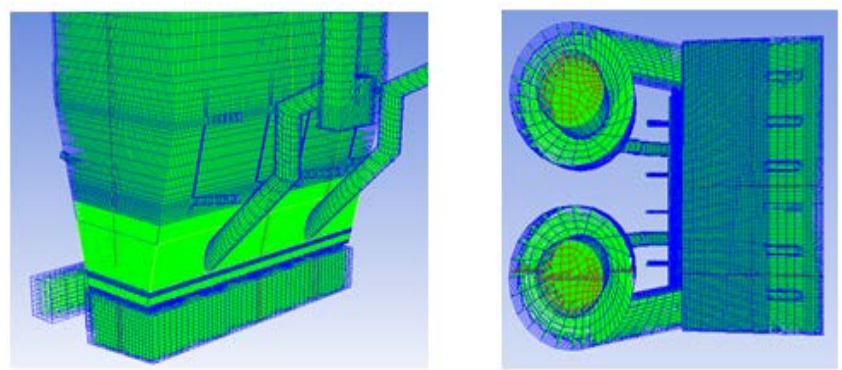

Figure 2. Mesh used for simulation

Mesh is the process of splitting the domain into smaller volumes. This is done to facilitate the discretization of the stream domain and apply control equations to the stream domain. Meshing used in the simulation process has the number of nodes 2,273,622.

\section{B. Solver Models}

In the simulation process, inputs are made to the model solver. Solver models used can be seen in the table below.

TABEL 1.

SOLVER MODELS OF SIMULATION

\begin{tabular}{ll}
\hline \multicolumn{2}{c}{ MoLVER MODELS OF SIMULATION } \\
\hline Multiphase & \multicolumn{1}{c}{ Information } \\
Energy & On \\
Viscous & $\mathrm{k}-\varepsilon$ standard \\
Radiation & Off \\
Heat exchanger & Off \\
Species & Species transport \\
Discrete phase & On \\
Solidification & Off \\
Acoustics & Off \\
Eulerian wall film & Off \\
\hline \hline
\end{tabular}

\section{Materials}

In the material arrangement, air is used with a density value of $0.295 \mathrm{~kg} / \mathrm{m}^{3}$, density of air under boiler operating conditions, and viscosity of $1.7894 \mathrm{e}^{0.5} \mathrm{~kg} / \mathrm{ms}$. In addition, aluminum material is used with density $2719 \mathrm{~kg} / \mathrm{m}^{3}$ as material from boiler walls. The following table can be seen properties used in coal.

TABEL 2.

PROPERTIES OF COAL

\begin{tabular}{lll}
\hline \hline \multicolumn{1}{c}{ Properties } & Value \\
\hline Density $\left(\mathrm{kg} / \mathrm{m}^{3}\right)$ & 1400 &
\end{tabular}

$\begin{array}{ll}\text { Cp (J/kg.K) } & 1500 \\ \text { Vaporation temperature } & 400 \\ \text { Volatile component fraction } & 34.5 \\ \text { Binary difusity } & 0.0005 \\ \text { Sweling coefficient } & 2 \\ \text { Combustile fraction (\%) } & 32.3 \\ \text { React heat fraction absorbed by solid } & 30 \\ \text { Devilitization model (1/s) } & 50 \\ \text { Combustion model } & \text { Multiphase surface reaction }\end{array}$

\section{Operating Conditions}

Operating condition is used to manage operational pressures within a simulated system. In this simulation, the operational pressure is set at pressure $101325 \mathrm{~Pa}$ and the effect of gravity on the negative y-axis direction (9.81 $\mathrm{m} / \mathrm{s}^{2}$ ).

\section{E. Boundary Conditions}

Boundary condition is a condition in the simulation modeling domain to approach the actual state. The boundary conditions and the type of boundary conditions desired will be determine at this stage. The boundary conditions for the boiler as a whole can be seen in the table below.

TABEL 3.

BOUNDARY CONDITION

\begin{tabular}{lccc}
\hline \hline Boundary condition & \multicolumn{1}{c}{ Type } & Fase & Information \\
\hline Primary air & Mass flow inlet & Air & $\mathrm{m}_{1}=6.077 \mathrm{~kg} / \mathrm{s}$ \\
& & & $\mathrm{m}_{2}=5.389 \mathrm{~kg} / \mathrm{s}$ \\
& & $\mathrm{P}=8.2 \mathrm{kPa}$ \\
& & & $\mathrm{T}_{1}=457.4 \mathrm{~K}$ \\
& Mass flow inlet & Air & $\mathrm{T}_{2}=495.8 \mathrm{~K}$ \\
\hline Secondary air & & & $\mathrm{m}_{2}=2.181 \mathrm{~kg} / \mathrm{s}$ \\
& & & $\mathrm{m}_{2}=2.167 \mathrm{~kg} / \mathrm{s}$ \\
& & & $\mathrm{T}_{1}=510.5 \mathrm{~K}$ \\
& & $\mathrm{~T}_{2}=495.4 \mathrm{~K}$ \\
\hline Coal inlet & Mass flow inlet & Coal & $\mathrm{m}^{2}=4.944 \mathrm{~kg} / \mathrm{s}$ \\
\hline Outlet & Pressure oulet & Mixture & $\mathrm{P}_{1}=-0.9 \mathrm{kP}$ \\
& & & $\mathrm{P}_{2}=-0.9 \mathrm{kP}$ \\
\hline \hline
\end{tabular}

\section{F. Data Variation}

The object for this research is circulating fluidized bed (CFB) boiler in steam power plant Bangka with $22.5 \mathrm{MW}$ (75\% MCR). This research was conducted by modeling using Computational Fluid Dynamics (CFD) software to simulate combustion with secondary air quantity changes. The values of secondary air used for this simulation are four variations.

TABEL 4

DATA VARIATION

\begin{tabular}{ccccc}
\hline \hline Primary air & Secondary air & AFR & Coal & $\begin{array}{c}\text { Equiv. } \\
\text { ratio }(\boldsymbol{\phi})\end{array}$ \\
\hline $\mathrm{m}=11.46 \mathrm{~kg} / \mathrm{s}$ & $\mathrm{m}=4.34 \mathrm{~kg} / \mathrm{s}$ & 3.52 & $\mathrm{~m}=4.94 \mathrm{~kg} / \mathrm{s}$ & 2.69 \\
$\mathrm{~m}=11.46 \mathrm{~kg} / \mathrm{s}$ & $\mathrm{m}=13.92 \mathrm{~kg} / \mathrm{s}$ & 5.46 & $\mathrm{~m}=4.94 \mathrm{~kg} / \mathrm{s}$ & 1.73 \\
$\mathrm{~m}=11.46 \mathrm{~kg} / \mathrm{s}$ & $\mathrm{m}=23.55 \mathrm{~kg} / \mathrm{s}$ & 7.40 & $\mathrm{~m}=4.94 \mathrm{~kg} / \mathrm{s}$ & 1.28 \\
$\mathrm{~m}=11.46 \mathrm{~kg} / \mathrm{s}$ & $\mathrm{m}=33.15 \mathrm{~kg} / \mathrm{s}$ & 9.34 & $\mathrm{~m}=4.94 \mathrm{~kg} / \mathrm{s}$ & 1.02 \\
\hline \hline
\end{tabular}




\section{RESULTS AND DISCUSSION}

\section{A. Superficial Velocity (y-axis) of Air}

Visualization of airflow velocity contours is used to show signs of vortex and backflow in the boiler, either in nozzle, furnace, or on cyclone. Vortex is a flow that forms like rotate caused by several factors such as molecular or particle viscosity, flow velocity and geometry that causes the direction of the flow to move against the flow direction and in circles. Separation or backflow is a flow that decreases the velocity caused by the friction between molecules or so-called viscosity and shear stress on the wall, so that when the velocity 0 began to occur backflow to form vortex.
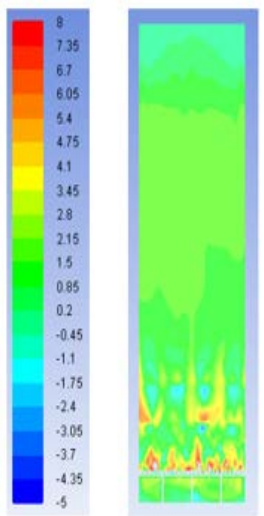

AFR 3.52

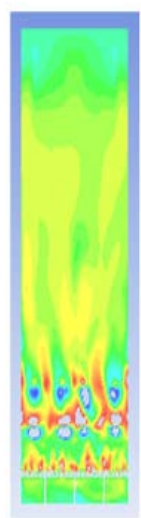

AFR 5.46

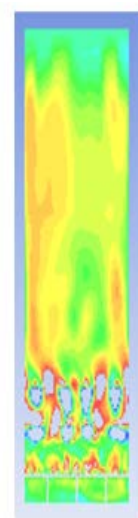

AFR 7.40

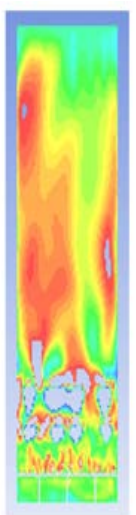

AFR 9.34
Figure 3. The superficial velocity contours of each air variation

From figure 3 can be seen the effect of mass flow from secondary air to superficial velocity. In the first variation, AFR 3.52, the average superficial velocity reaches 2.18 $\mathrm{m} / \mathrm{s}$. In this variation, the air velocity distribution tends to be evenly distributed in all parts of the furnace. But with this velocity, air unable to lift the sand particles and the fluidization process does not work properly.

In the second variation, which is AFR 5.46, the superficial distribution of velocity tends to resemble the distribution of the first variation. By increasing the mass flow of secondary air, the superficial velocity of the boiler will increase as well. However, in the area close to the inlet secondary air, make downward velocity to around $-5 \mathrm{~m} / \mathrm{s}$. It will affect the particle sand distribution as well as the flow from below, which is from the primary air.

In the third variation, with the mass flow secondary air of AFR 7.40, the velocity on the y-axis can reach $5.4 \mathrm{~m} / \mathrm{s}$. In this variation, superficial velocity along the boiler is good enough to make sand particle fluidized. But in AFR 9.34, superficial velocity exceeds $6.7 \mathrm{~m} / \mathrm{s}$. This can make a particle sand located on the area raised to the top of the boiler. In addition, areas that have velocity toward the negative y-axis is increase. It is also seen that air has high superficial velocity in the middle of the boiler. In the central area of the boiler, fluid tends not to be affected by the shear stress in the area around the boiler wall.

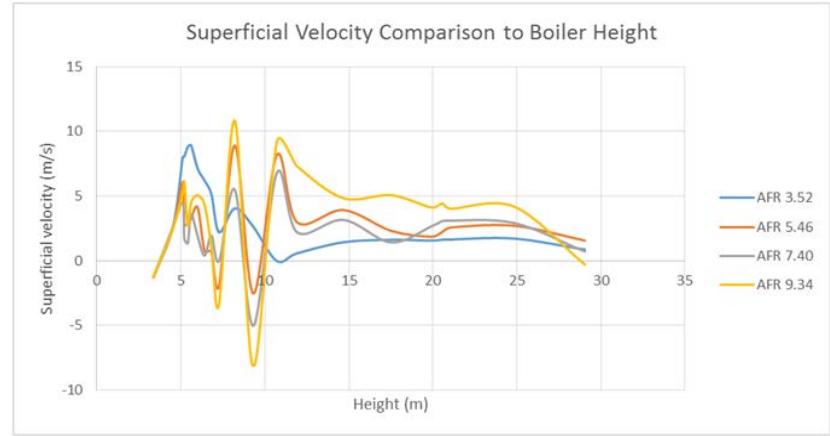

Figure 4. Graph of superficial velocity at different height

In evaluation of the fluidization process, also done by evaluating the graph of air velocity. In figure 4 shows a graph of superficial air velocity to the height of the boiler. On the graph it can be seen that in the area above the windbox, which is a height of $5 \mathrm{~m}$, has the highest velocity. Along with the increase of height position, the air velocity will decreases. Air velocity decreases especially as it passes through the fluidized area of the sand particle. After passing the particle sand area, at height of $13 \mathrm{~m}$, the air velocity is relatively constant. This is because the flow from the air is no longer affected by disturbance, ie sand particle and secondary air flow. While at a height of $28 \mathrm{~m}$, the flow from the air leads to the negative y-axis. This point is at the top of the ducting leading to the cyclone, so the airflow will move toward the negative $y$-axis.

\section{B. Pressure of Boiler}

Visualization of the pressure contours used to determine the level of pressure under certain conditions. Pressure contours are also used to determine the pressure drop in the boiler.
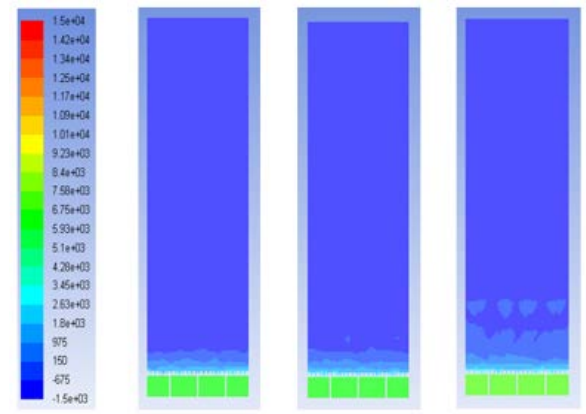

AFR 3.52

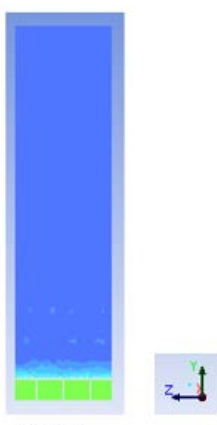

AFR 9.34

Figure 5. Contours of pressure of each secondary air variation

On the countours it can be seen that the pressure generated on the combustion chamber is strongly influenced by sand particle. The pressure generated with AFR 5.46 is about $6642.3 \mathrm{~Pa}$ in the windbox area, and in the middle furnace area about $-868.6 \mathrm{~Pa}$. The pressure on the area is quite high due to the sand particle in the area close to the noozle, so the pressure will rise. With high pressure on this windbox area, air flow will move to the higher pressure part, that is upper furnace area or close to the outlet. This will help the movement of the resulting flue gas. From the simulation results, the pressure generated on the upper furnace is strongly influenced by the outlet pressure in the area close to the cylone.

$$
\frac{\Delta P}{L}=150 \frac{(1-\epsilon)^{2} \mu U}{\epsilon^{3} d_{p}^{2}}+1.75 \frac{(1-\epsilon) \rho_{\mathrm{g}} U^{2}}{\epsilon^{3} d_{p}}
$$


In the above equation we can know the relationship between several parameters of the operation against changes in pressure in the combustion chamber. [2] Some parameters such as the distance of both test points, gas viscosity, superficial velocity, and gas density will make the pressure change will be greater. While other parameters, such as voidage and particle diameter will make the difference between the pressures of the two points become decrease.

\section{Distribution of Sand Particle}

Contours of volume fraction visualization is used to determine the distribution of sand particles along the boiler. This countours is taken at a certain time, so the movement tendency of particle can be known.
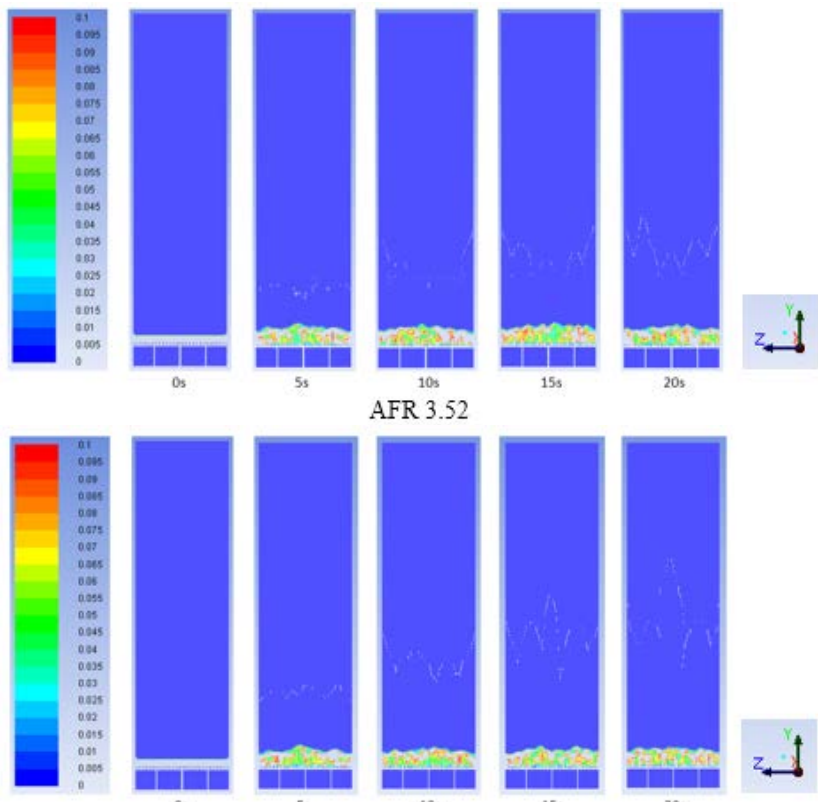

AFR 3.52
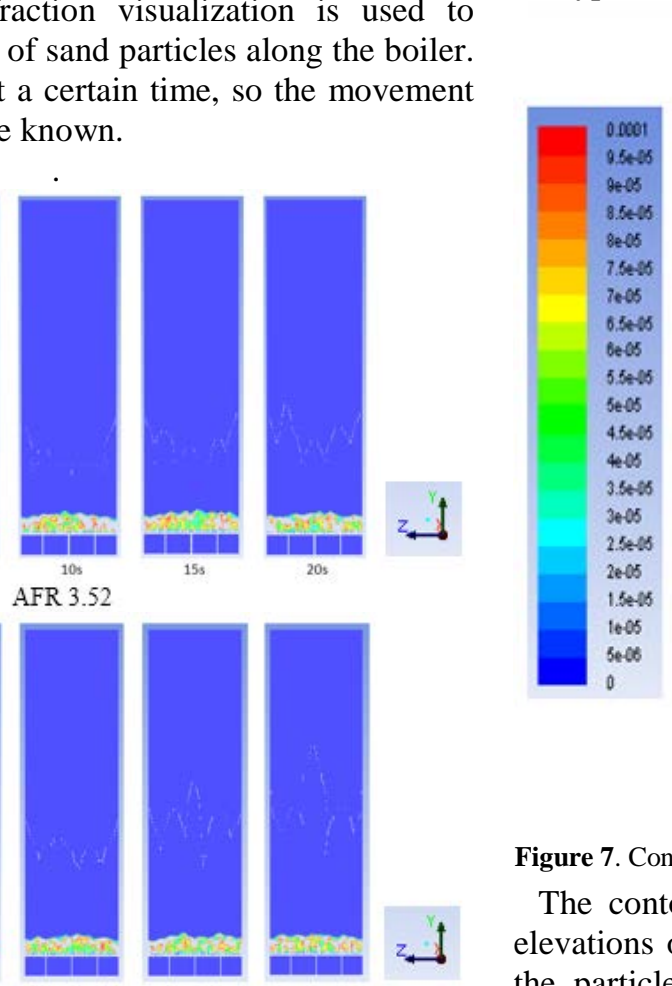

From figure 6 can be seen the change of contour and movement sand particle during certain time. Contour retrieval is done at time step to $0 \mathrm{~s}, 5 \mathrm{~s}, 10 \mathrm{~s}, 15 \mathrm{~s}$, and $20 \mathrm{~s}$. In the picture we can see the movement of the particle sand that was originally at the bottom of the boiler, then lifted up and will be fluidized. At the time when fluidizing air flow is too big, the particle sand is raised in number will increase too. With the change of time, the raised particle sand will accumulate in the cyclone. With the time step difference, the tendency of sand particle movement can be known, and the type of fluidization that occurs can be analyzed.

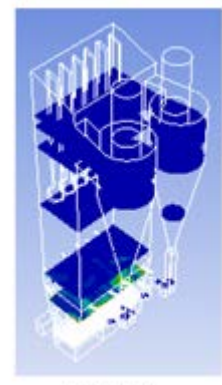

AFR 3.52

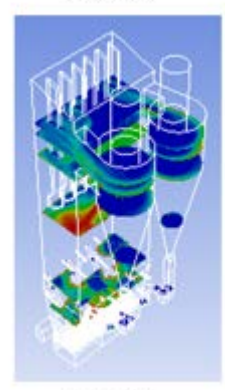

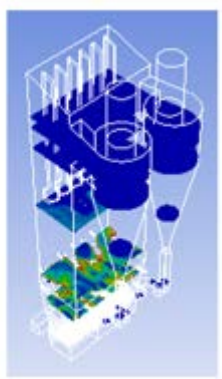

AFR 5.46

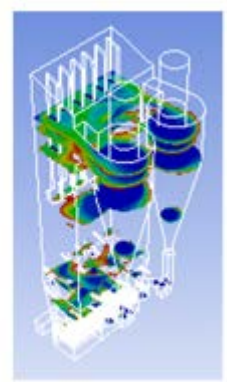

AFR 9.34
AFR 7.40

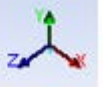

Figure 7. Contour volume fraction of sand particle at specific boiler height

The contour of the fraction volume is taken at several elevations on plane-xy. In the figure 7 can be seen where the particle sand gathering area. Given the influence of mass secondary air flow changes, the area where the particle operates undergoes changes. In mass flow prior to AFR 3.52, the operating area of the sand particle tends to be lower furnace. Due to superficial air velocity in this variation is low, so almost all sand particle classified into fixed bed. While in AFR 5.46, the particle position tends to raise compared to AFR 3.52. In this mass flow, there is a characteristic bubbling and turbulent bed formed. At the time of AFR 7.40, many particles are lifted to the top of the boiler. In this case, the position of the particle sand is no longer near the nozzle. This keeps many particles moving up and down throughout the boiler, as well as the circulation rate will increase. At the last variation, which is AFR 9.34, the particle position will be almost on half the boiler. In this state many particles in the state of fast beds, namely in a state of high velocity and continue to circulate.

At the time of the mass flow variation of secondary air, we can see the distribution and contour of the fraction volume of the sand particle. When the value of AFR is 3.52, the number of sand particles raised up to the top of the boiler is not too much. The particle sand will always circulate along the boiler, where the initial state is at the bottom of the boiler, up to the boiler, then into the cyclone, through the return leg, and back to the boiler again. At the

Figure 6. Contour the fraction volume of the sand particle on the yz-plane (time dependent) 
time of the addition mass flow of secondary air, raised sand particle amount will raise, and make the circulation of sand particle increase too. This will make the particle sand collide with the boiler parts, such as superheater and waterwall. This factor can be one of the causes of erosion in some parts of the boiler.

With the volume fraction contour, we can make fluidization grouping. The groupings are divided into 4 groups, and can be analyzed on the fraction volume of the sand particle and superficial velocity from the air. [7] At the condition of the particles are at rest, then this type of fluidization is called static bed. During static bed conditions, the air velocity of fluidization is at $0-3 \mathrm{~m} / \mathrm{s}$. Sand particle which is included into the condition are some particles that are on the bottom of the boiler. The second type is the particles in the bubbling bed state. The movement of the sand particle is higher than static bed and the particles start expanding, but superficial air velocity is still below the velocity terminal of the sand particle. The third type is when the sand particle is fluidized and moves up and down along the boiler, which can be called turbulent bed. This can be known from the solid volume fraction and velocity gas close to the superficial air velocity, and the particle distribution is quite evenly distributed. When particles have this property, the particles move up and down along the combustion chamber, but do not get to the cyclone. While the last type is fast bed, where the particles in this state has the highest circulation rate. In this type, the particle sand velocity will be quite high, causing erosion on the boiler section.

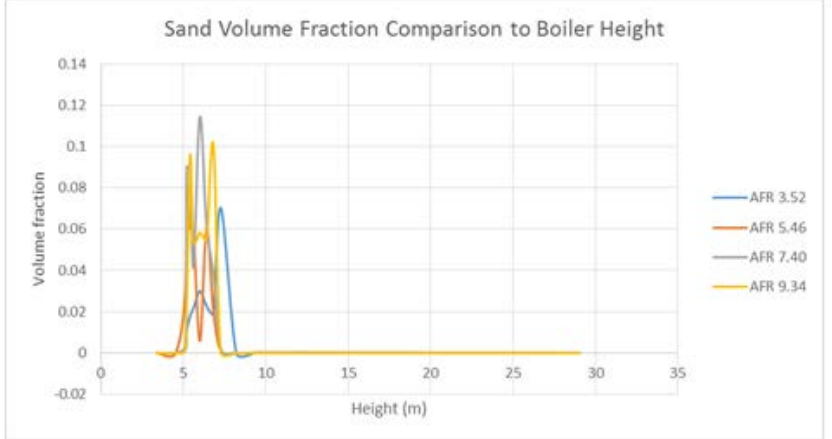

Figure 8. Graph of volume fraction at different height

From figure 8 can be seen graph of fraction volume of sand particle to boiler height. Based on the graph can be known the area of sand particle distribution. In the graph, it can be seen that the sand particle diffuses at a height of $5 \mathrm{~m}$ to $8 \mathrm{~m}$. This is because the location of the nozzle is up to a height of $5.2 \mathrm{~m}$, so the sand particle may not be under nozzle (inside windbox). From the figure can be seen that at the time of mass flow secondary air is low, that is equal to AFR 3.52 and AFR 5.46, volume fraction distribution tends to evenly to boiler height. While the secondary air mass flow is high, which is equal to AFR 7.40 and AFR 9.34, the volume fraction distribution of the secondary air tends to fluctuate. This is due to the secondary air direction to down, while the direction of primary air to the top. With different directions inlet air, will make sand particle will be spread unevenly.

Gravitational force $=$ Buoyant force + Drag force

$$
\rho_{p} \mathrm{~g}=\rho_{p} \mathrm{~g}+C_{D} \frac{6(U-v)^{2} \rho_{\mathrm{g}}}{8 d_{p}}
$$

When the gravitational force acting on the particles is larger than the sum of the buoyant force and the drag force, the particles tend not to rise up and are in bottom of boiler. Conversely, if the gravitational force of the particle is smaller than the sum of buoyant force and drag force, then the particle will be fluidized or lifted.[2]

\section{G. Velocity of Secondary Air}

Visualization of sand particle speed is used to determine the level of erosion in the boiler, and areas prone to erosion. The particle sand velocity contours are also used to determine the circulation as long as the boiler has gone well.

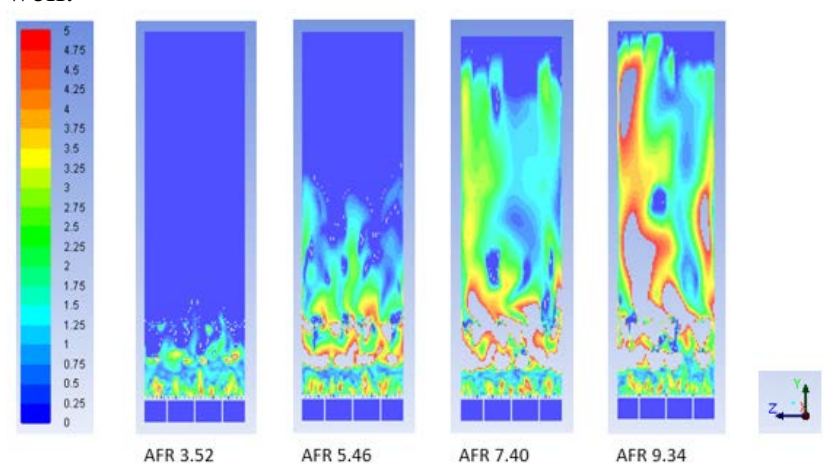

Figure 9. Contour of sand velocity at each variation

Based on figure 9 can be seen the influence of secondary air flow mass variations to the speed of sand particle. In AFR 3.52, sand particle speeds range from $1 \mathrm{~m} / \mathrm{s}$ to 3.25 $\mathrm{m} / \mathrm{s}$. The particle sand velocity distribution is also relative evenly on the bottom of the boiler. With this low speed, almost all parts of sand particle classified into fixed bed. At AFR 5.46, the speed of sand particle is higger than mass flow secondary air of AFR 3.52. In addition, some particles are also lifted from moving up and down along the combustion chamber. In this mass flow, there is a characteristic bubbling and turbulent bed formed. This will make the burning process more optimal. At the time of AFR 7.40, many particles are lifted to the top of the boiler. In this state, the superficial air velocity exceeds the velocity terminal of the sand particle. This keeps many particles moving up and down throughout the boiler, as well as the circulation rate will increase. While at the last variation AFR 9.34, the particle velocity exceeds $5 \mathrm{~m} / \mathrm{s}$ and many particles are lifted to the top of the boiler. In this state many particles in the state of fast beds, namely in a state of high speed and continue to circulate.

Based on the metal cutting theory of Finni (1960), experimental data, and the Chinese Boiler Thermal Standard (1973) make the equation for maximum erosion occurring on the boiler tube. [2]

$$
E_{\text {max }} \propto M \tau \rho_{\mathrm{a}} V_{\mathrm{g}}^{3.3}
$$

In the above equation, the erosion occurring in the boiler is strongly influenced by the speed of the sand particle. At the time the particles collide with the boiler wall, the particles will crash with impact force at a certain angle and a certain speed. This impact force can be divided into 2 
components, ie the normal force that will cause deformation in the material, and force parallel to the surface that will release material from the surface. The rate of erosion will occur maximum at the time of impact angle around $45^{\circ}$. In addition to causing erosion on the boiler walls, sand particle will also affect the movement of particles one with other particles. This is due to the momentum between the particles, either when the two particles are moving or when only one of the particles is moving.

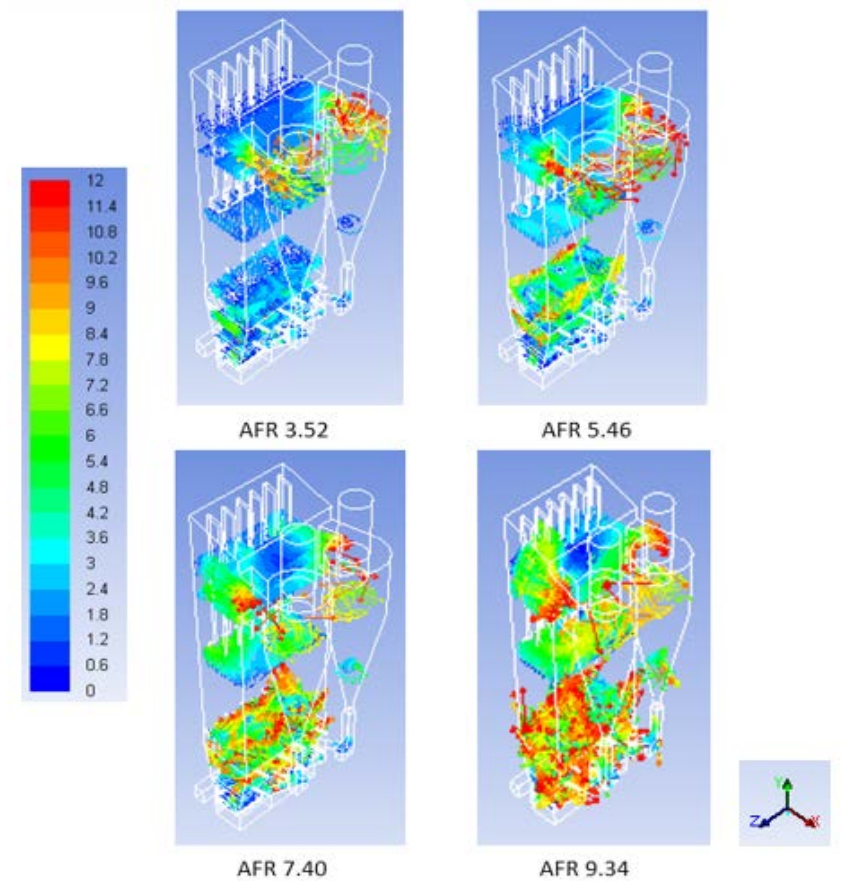

Figure 10. Vector of air at specific boiler heights

In figure 10 we can see the direction of the vector from the air at some boiler height. With the mass flow variations cause changes in the resulting air velocity. In the lower furnace area, mass flow changes significantly cause changes in air velocity, especially in areas close to the boiler walls. In the upper furnace area, variations in mass flow secondary air cause changes in air velocity, especially in the cylone area. In the cyclone area, the air velocity during AFR 9.34 can make the air velocity in the area reach $12 \mathrm{~m} / \mathrm{s}$.

\section{CONCLUSION}

The movement of sand particle will be greatly influenced by mass flow from air. Secondary air will affect to particle sand distribution and superficial air velocity. At AFR 5.46, the sand particle reaches only the middle of the furnace, with superficial velocity at the top of the bed around 4.1 $\mathrm{m} / \mathrm{s}$. The pressure generated with AFR 5.46 is about 6642.3 $\mathrm{Pa}$ in the windbox area, and in the middle furnace area about -868.6 Pa. At the time of AFR of 3.52, bed material formed in the form of static bed. At AFR 5.46 and AFR 7.40 , bed material formed is bubbling and turbulent bed. While at highest secondary air which is AFR 9.34, bed material will form fast bed.

\section{ACKNOWLEDGEMENT}

The authors are grateful to Bambang Sudarmata as advisory lecturer, Giri Nugroho for providing the blueprint of the boiler, and to Achmad Syaifudin for discussion on the simulation. This work was supported by the PT PJB Services.

\section{NOTATION}

$\Delta \mathrm{P} \quad=$ pressure change

$\mathrm{L} \quad=$ distance between the two points

$\epsilon \quad=$ voidage (gap on packed bed)

$\mathrm{U} \quad=$ superficial speed as it passes through the packed bed slot

$\mu \quad=$ gas viscosity

$\mathrm{d}_{\mathrm{p}} \quad=$ particle diameter

$\rho \mathrm{g} \quad=$ gas density

$\rho_{\mathrm{p}} \quad=$ particle density

$\rho_{\mathrm{a}} \quad=$ density of fly ash

$\mathrm{C}_{\mathrm{D}}=$ drag coefficient

$\mathrm{E}_{\max }=$ maximum erosion

$\mathrm{M}$ = coefficient of erosion resistance the material $(\mathrm{M}=1 \mathrm{for}$ carbon steel, $\mathrm{M}=0.7$ for alloy steel)

$\tau \quad=$ erosion time of the tube (hours)

$\mathrm{V}_{\mathrm{g}} \quad$ = gas velocity passing through the tube

\section{REFERENCES}

[1] Direktorat Jenderal Ketenagalistrikan, Statistik Ketenagalistrikan 2015. Jakarta: Direktorat Jenderal Ketenagalistrikan, 2016.

[2] P. Basu, Circulating Fluidized Bed Boilers. Cham: Springer International Publishing, 2015.

[3] Pandey K. M and R. Kumar, "Numerical Analysis of Coal Combustion in Circulating Fluidized Bed," Int. J. Chem. Eng. Appl., vol. 2, no. 6, pp. 390-394, 2011.

[4] B. Sudarmanta, "Dual fuel engine performance using biodiesel and syn-gas from rice husk downdraft gasification fo power generation,” in International Seminar on Sustainable Biomass Production and Utilization: Challenges and Opportunities, 2015.

[5] N. Zhang, B. Lu, W. Wang, and J. Li, "3D CFD simulation of hydrodynamics of a 150 MWe circulating fluidized bed boiler," Chem. Eng. J., vol. 162, no. 2, pp. 821-828, Aug. 2010.

[6] PJB Services, TOR Simulasi CFD PLTU Bangka. Sidoarjo.

[7] UNEP, "Biomass Fired FBC Boiler for Cogeneration." 